\title{
The Use of Computerised Dynamometry to Quantify Functional Grip and Release in People Post Stroke: A Pilot Study
}

\author{
Ian J. Baguley ${ }^{*}$, Melissa T. Nott and Hannah L.H. Barder
}

Brain Injury Rehabilitation Service, Westmead Hospital, Westmead NSW 2145, Australia

\begin{abstract}
Purpose: To present a theoretical construct and pilot data from an analytic technique to simultaneously quantify positive and negative upper motor neuron (UMN) features.

Method: Computerised hand dynamometry was used to measure hand contraction-relaxation cycles during a repetitive grasp and release task. Measurements of force, time, force velocity and 'grip work' were collected on a pilot sample of 5 post-stroke subjects and 5 matched controls. Within and between group differences were analysed.

Results: Force, time and velocity dependent aspects of hand performance did not differ between the dominant and nondominant upper-limbs of control subjects. In contrast, the post-stroke group generated less grip force over longer cycle times with their affected limb, consistent with negative UMN features. In controls, $97 \%$ of grip work was task specific, with 3\% associated with involuntary, non-task grip work. Conversely, the post-stroke group generated high levels of involuntary, non-task grip work (39\%), a feature consistent with positive UMN features of muscle overactivity. Force velocity and maximal force were lower in the non-affected limbs of the stroke group than matched dominant limbs of the control group, supporting functional Magnetic Resonance Imaging data that the function of non-affected cerebral hemisphere is abnormal following stroke.

Conclusions: The computerised dynamometry analysis paradigm was able to simultaneously quantitate aspects of hand performance affected by positive and negative UMN features within an individual and between groups. This approach uses a clinically relevant, functionally based assessment technique that appears to have greater ecological validity and fewer limitations than current measures of spasticity.
\end{abstract}

Keywords: Hand dynamometer, muscle spasticity, assessment, stroke, grip work.

\section{INTRODUCTION}

The motor abnormalities following upper motor neuron (UMN) lesions are conceptualised as having positive and negative components $[1,2]$. The negative features of UMN syndromes relate to loss of normal motor recruitment patterns and are evidenced by loss of strength, reduced fine motor control, incoordination and so on. Conversely, the positive features arise from uncontrolled muscle overactivity, seen as spasticity, increased tone, agonist/antagonist co-contraction, etc.

While the negative features have been reported as more troublesome to patients with UMN lesions [3-5], the advent of potent agents that modify positive UMN features (such as Botulinum Toxin A and intrathecal baclofen) has increasingly led researchers to focus on positive features. This process of focusing attention on positive UMN features has highlighted the limitations of current assessment methods and difficulties surrounding nomenclature. For example, although the term 'spasticity' has a precise definition [6], it is often used as an 'umbrella term' encompassing the other positive UMN features [7]. This umbrella grouping of several positive UMN features under

*Address correspondence to this author at the Research Team Leader, Brain Injury Rehabilitation Service, Westmead Hospital, Westmead NSW 2145, Australia; Tel: (612) 9845 7941; Fax: (612) 9635 8892;

E-mail: ianb@biru.wsahs.nsw.gov.au one term may explain the differences between the Tardieu Scale $[8,9]$, a measure of the formal definition of spasticity, and the Modified Ashworth Scale (MAS) [10] which measures several different positive features in combination. The MAS, previously held as the gold standard in spasticity assessment, demonstrates lower reliability and validity compared to the Tardieu Scale $[8,9,11-13]$.

In addition to uncertain measurement reliability and validity, both the Tardieu and MAS measure human performance at the 'body structure and function' level of the International Classification of Functioning (ICF) [14]. Measurement of muscle spasticity at the body structure and function level is only useful if there is a specific, sensitive and reproducible association between the spasticity measure and an individual's degree of function at the 'activity or participation' levels of the ICF. A small number of studies have identified an association between the MAS and measures of either active [15] or passive function (that is, improved hygiene or reduced carer burden) [16, 17]. However, these studies have demonstrated moderate associations at best, in very limited samples and contexts.

Other techniques for measuring the effect of spasticity on motor function have been developed, such as electromyography (EMG) [15, 17-19] and various mechanical devices. These latter devices generally measure passive range of motion (ROM) by fixing the subject's affected hand onto/into a device and applying consistent 
torque during goniometry $[20,21]$. Other devices have been designed to measure the force generation in affected muscles (i.e. wrist flexors) by attaching spring-weighted devices to the affected hand $[20,22]$. These devices lack versatility and clinical utility, as their use is limited to those subjects who have sufficient ROM to adopt the position in which the hand is measured; that is, fastened to a board or fitted into a splint or cuff.

\section{ASSESSING UPPER LIMB FUNCTION FOLLOWING UMN LESIONS}

To properly evaluate functional improvement in hand performance following an UMN lesion, assessment tools need to measure within the 'activity and/or participation' domains of the ICF [14]. Burridge et al.'s [23] review on spasticity found that few quantitative tools exist to measure the behaviour of spastic muscle during functional activity.

Measurement of grip strength is a well established method for investigating hand function, providing insight into the combined action of extrinsic and intrinsic muscle groups [24]. Hand-held mechanical dynamometers record the maximal grip strength attained during a period of effort, thereby assessing a subject's hand strength against normative data with excellent inter-rater and test-retest reliability [25].

A newer approach to grip strength assessment is the use of computerised dynamometers. These devices record force generation as a vector measurement (that is, one with both a magnitude $(\mathrm{kg})$ and a direction (contraction-relaxation)). Computerised dynamometry has excellent test-retest reliability $(r=0.97-0.98)$ [26], rater reliability $(r=0.91-0.93)$ [24] and measurement sensitivity levels below those detectable with mechanical dynamometers [27]. Most importantly, force/time analysis from computerised dynamometry demonstrates moderate to high correlation with categorical measures of upper limb function $(\mathrm{r}=0.74-$ 0.83) $[28,29]$.

Force/time analysis from computerised dynamometry has enabled measurement of post-botulinum toxin changes in grip strength [30], associated reactions after stroke [31, 32], submaximal effort during upper-limb assessment [33,34], and 'grip work' - the amount of work undertaken by an individual during isometric force generation [35, 36]. In addition to hand function assessment, electronic dynamometers have been used as a rehabilitation tool to improve motor control of finger contraction and relaxation [24, 37].

These studies highlight existing methods for analysing force/time data derived from computerised dynamometry. This paper outlines additional analysis paradigms to investigate the grasp and release function of the hand. This analytic approach builds on the conceptual basis of force/time vector analysis, combining these data with changes observed in hand function following an UMN lesion. From this integrated conceptual basis, a theoretical construct was developed and piloted with a small sample of adults demonstrating post-stroke upper-limb UMN features and a non-injured control group.

\section{HYPOTHESES}

Based on previous computerised dynamometry research and motor recovery data, it was expected that there should be:
1. No significant difference between the dominant and non-dominant hands of controls,

2. A significant difference between the affected and non-affected hands of the post-stroke group, and

3. No significant difference between values for the dominant hand of controls and the non-affected (poststroke dominant) hand of the post-stroke group.

\section{MATERIALS AND METHODS}

\section{Research Design and Participants}

Following approval by the local institutional ethics committee, 10 subjects were recruited under the study protocol. All subjects provided written informed consent. Subjects in this pilot phase were a convenience sample of five adults a minimum of nine months post-stroke, who were receiving physical or pharmacological intervention at an outpatient spasticity management clinic of a metropolitan hospital. Subjects were two males and three females, mean age was 54 years $(\mathrm{SD}=17)$, two were left dominant and three were right dominant. Five non-injured controls were gender, hand dominance and age matched from staff volunteers at the hospital with a mean age of 51 years $(\mathrm{SD}=8)$. Subject characteristics are outlined in Table $\mathbf{1}$.

\section{Data Collection and Analysis}

This research protocol assessed hand grasp and release during repetitive maximal force generation. During data collection, participants were seated in a chair with arm rests or in their wheelchair. Upper limb position was standardised with the elbow supported at $90^{\circ}$ flexion, forearm positioned in neutral, allowing $0-30^{\circ}$ wrist extension and $0-15^{\circ}$ ulnar deviation [33]. Both upper limbs were assessed; hand dominance and the stroke affected side were recorded. The computerised hand dynamometer (G100 Precision Dynamometer; Biometrics Pty Ltd; Jamar configuration) was attached to a laptop computer with real time data capture and visual display.

\section{Force Curve and 'Grip Work'}

Data were processed off-line to identify maximal force generation in $\mathrm{kg}$ and the duration of each contractionrelaxation cycle in ms (displayed as Force curve ( $\mathrm{F}$ curve) in Fig. 1). The first integral of the $F$ curve (area under the curve) gives a value of the 'grip work' undertaken by the individual during each contraction/ relaxation cycle. In addition, by determining the time and amount of force exerted at onset and offset of contraction and relaxation (i.e. preparing to contract and release), an estimate of 'non-task grip work' could be made (see Fig. 1).

\section{Force Velocity Curve}

The first derivative of the $F$ curve was calculated to evaluate rate of change in force generation over time (termed Force velocity $\left.\left(\mathrm{F}_{\mathrm{vel}}\right)\right)$. This approach to evaluating $\mathrm{F}_{\mathrm{vel}}$ enabled the myoneural process of contraction-relaxation to be more readily interpreted. The $F_{\text {vel }}$ curve in Fig. (2) is derived from the $\mathrm{F}$ curve in Fig. (1). The $\mathrm{F}_{\mathrm{vel}}$ curve includes two distinct phases (above and below the zero line). Conceptually, the contraction and relaxation phases of the $\mathrm{F}_{\text {vel }}$ curve correspond to the recruitment of flexor muscles during formation of a power grip and their subsequent 
Table 1. Subject Demographics and Injury Related Information

\begin{tabular}{|c|c|c|c|c|c|}
\hline & Subject 1 & Subject 2 & Subject 3 & Subject 4 & Subject 5 \\
\hline $\begin{array}{l}\text { Demographic } \\
\text { information: }\end{array}$ & $\begin{array}{c}36 \text { years; male } \\
\text { R dominant }\end{array}$ & $\begin{array}{l}49 \text { years; female } \\
\text { R dominant }\end{array}$ & $\begin{array}{l}46 \text { years; female } \\
\text { L dominant }\end{array}$ & $\begin{array}{l}81 \text { years; female } \\
\text { R dominant }\end{array}$ & $\begin{array}{c}59 \text { years; male } \\
\text { L dominant }\end{array}$ \\
\hline CVA: & MCA infarct & $\begin{array}{l}\text { Pontine cavernoma } \\
\text { haemorrhage \& } \\
\text { excision }\end{array}$ & Records unavailable & Basal ganglia infarct & Lacunar infarct \\
\hline Time post CVA: & 1 year & 9 months & 12 years & 4 years & 20 months \\
\hline UL presentation: & $\begin{array}{l}\text { L hemiplegia } \\
\uparrow \text { tone, pain, } \\
\text { spasticity, } \\
\text { subluxation, } \\
\text { clonus, hyper- } \\
\text { reflexia, } \downarrow \text { power } \\
\text { Non-functional UL } \\
\text { Set-up assist self- } \\
\text { care }\end{array}$ & $\begin{array}{c}\text { L hemiplegia } \\
\text { L sensory loss } \\
\downarrow \text { PROM, pain, } \\
\downarrow \text { power } \\
\text { UL functional } \\
\text { stabiliser } \\
\text { Set-up assist self- } \\
\text { care }\end{array}$ & $\begin{array}{c}\text { R hemiplegia } \\
\text { spasticity, wearing } \\
\text { resting splint and } 2^{\text {nd }} \text { skin } \\
\text { garment } \\
\text { Limited hand movement }\end{array}$ & $\begin{array}{c}\text { L hemiplegia } \\
\uparrow \text { tone; spasticity, nil clonus } \\
\text { Assisted self-care }\end{array}$ & $\begin{array}{c}\text { R hemiplegia } \\
\text { Non-functional UL } \\
\uparrow \text { tone, full PROM, } \\
\downarrow \text { AROM, } \downarrow \text { power } \\
\text { Limited hand movement } \\
\text { Assisted self-care }\end{array}$ \\
\hline
\end{tabular}

$\mathrm{CVA}=$ cardiovascular accident; $\mathrm{MCA}=$ middle cerebral artery; Records unavailable = CVA occurred in country of origin prior to migrating to Australia; PROM = passive range of motion; $\mathrm{AROM}=$ active range of motion; $\mathrm{L}=$ left; $\mathrm{R}=$ right; $\mathrm{UL}=$ upper-limb.

relaxation. The contraction, transition, and relaxation phases are outlined in Fig. (2) and described below.

Contraction phase $=$ period of increasing finger flexor recruitment and force generation; onset is represented by the time from initial increase in $\mathrm{F}_{\text {vel }}$ (i.e. consistently positive $\mathrm{F}_{\mathrm{vel}}$ values), through to maximal force generation (where $\mathrm{F}_{\mathrm{vel}}=$ $0 \mathrm{kgms}^{-1}$ ). Theoretically, change in $\mathrm{F}_{\mathrm{vel}}$ corresponds to motor unit recruitment strategies.
Transition $=$ period of minimal change during which $\mathrm{F}_{\mathrm{vel}}=0 \pm 0.01 \mathrm{kgms}^{-1}$; in control subjects occurring at the transition between contraction and relaxation phases.

period of flexor muscle relaxation (potentially including finger extensor activation) represented by consistently negative $F_{v e l}$ values. The slowing of relaxation towards $0 \mathrm{kgms}^{-1}$ corresponds with minimal grip strength for that cycle.

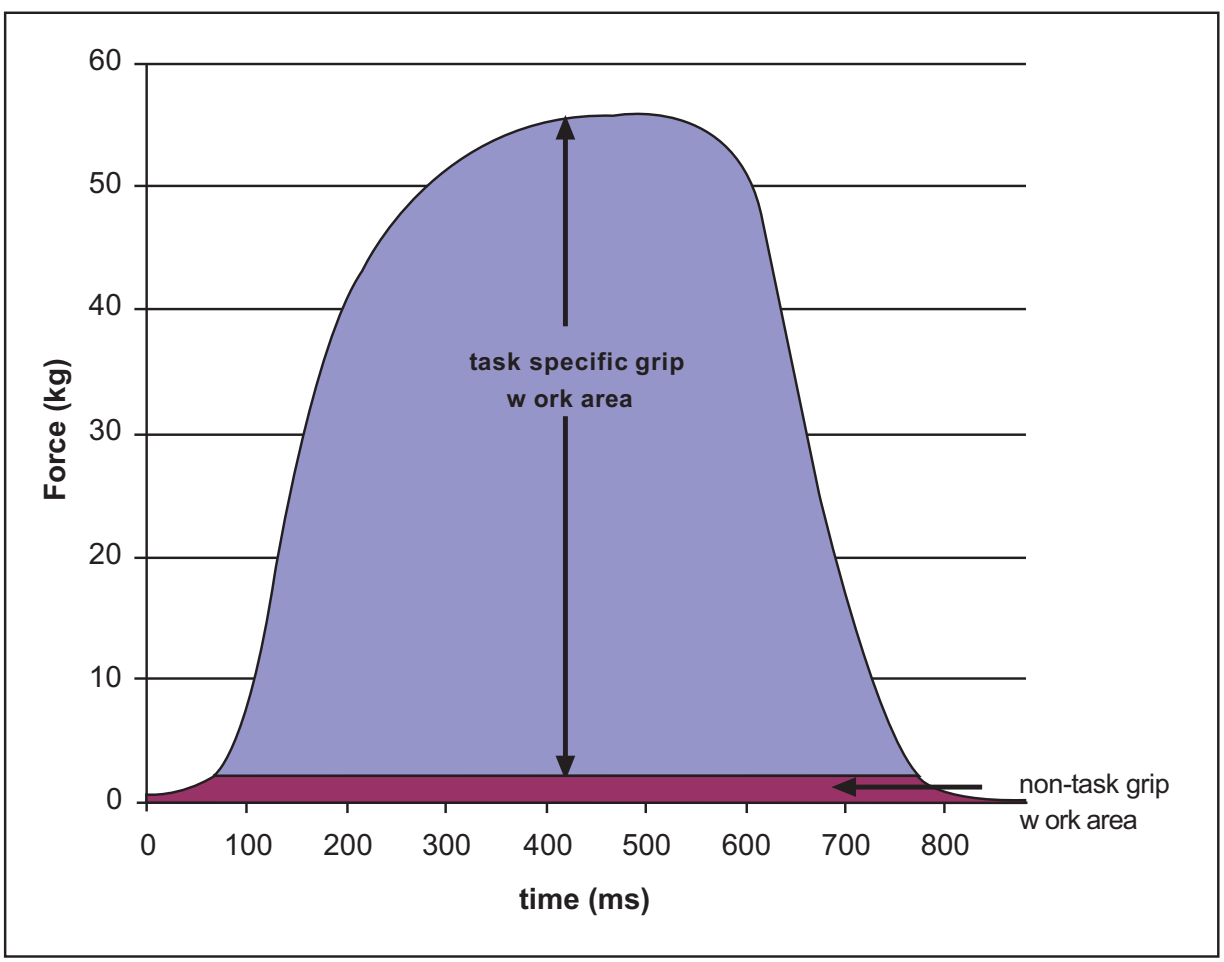

Fig. (1). Force curve for a right handed male control: maximal contraction and relaxation with areas of task specific grip work and non-task grip work identified. 


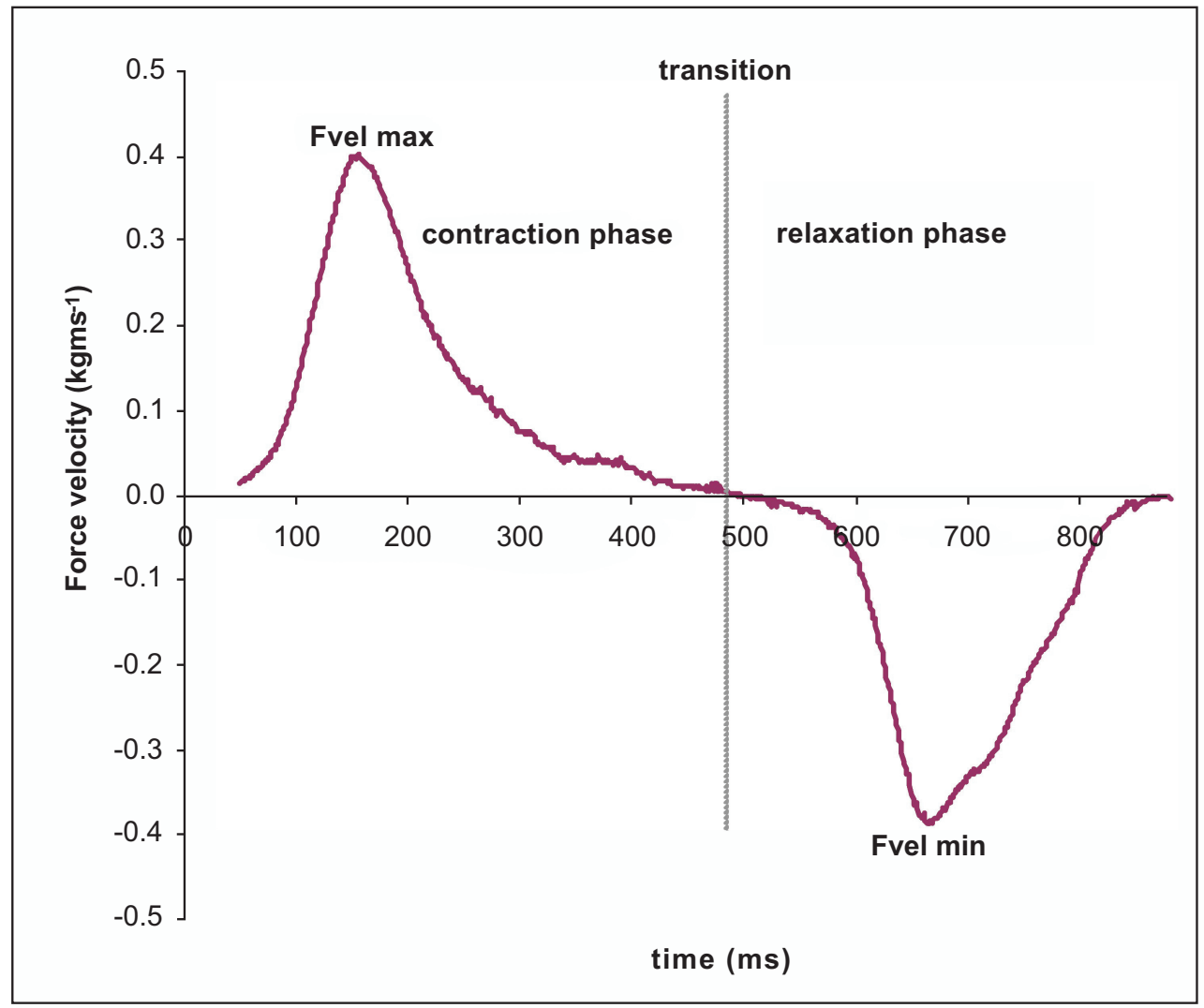

Fig. (2). Force velocity $\left(\mathrm{F}_{\mathrm{vel}}\right)$ curve for right handed adult male control displaying contraction, transition and relaxation phases.

Several quantitative indices were derived from the $F_{\text {vel }}$ analysis, including maximal rate of contraction and relaxation, and the time taken to achieve maximal contraction, relaxation and the transition point between contraction and relaxation.

\section{Repeated Grasp and Release}

Evaluation of multiple contraction-relaxation cycles (shown in Fig. 3) is known to encourage maximal grip force generation [34] and provided additional information about hand function after UMN lesions. The data derived from $\mathrm{F}$ and $F_{\text {vel }}$ curves for repeated cycles can be used to identify effects of motor learning (i.e. fine-tuning of task performance), consistency of response and fatigue. Observing repeated cycles enabled the time taken and degree of relaxation between sequential maximal contractions to be recorded, allowing for this form of 'non-task grip work' to be calculated. To reduce between cycle variation, data from cycle 1 were excluded from all analyses, effectively providing 9 cycles for data analysis. The average number of cycles recorded was 7.6 as two subjects were unable to complete 10 repeated contraction-relaxation cycles.

\section{Statistical Analysis}

All measures of hand grasp and release derived from the $F$ and $F_{\text {vel }}$ curves were averaged for each subject across the number of available trials. Between trial values for time and work were calculated from the repeated maximal contraction and relaxation $\mathrm{F}$ curve. Cycle duration and time between cycles is reported in $\mathrm{ms}$, while force is reported in $\mathrm{kg}$. Force velocity values are expressed as $\mathrm{kgms}^{-1}$, grip work values are expressed in kilogram.seconds (kg.s). Involuntary grip work is calculated as the sum of non-task specific work and the work performed between cycles. This is expressed as a percentage of the overall work performed (sum of taskspecific, non-task specific and between cycle work).

All data were entered and analysed in SPSS (version 17.0). Differences between dominant and non-dominant upper-limbs of the control group, then non-affected and affected upper-limbs of the post-stroke group were compared using non-parametric Wilcoxon Signed Ranks Test. Differences between the control and post-stroke groups were contrasted using Mann Whitney U Tests for independent samples. All comparisons were considered significant at $\mathrm{p} \leq$ .05 .

\section{RESULTS}

\section{Grip Force and Timing of Contraction-Relaxation Cycles}

The control group performed an average contractionrelaxation cycle with their dominant hand in $846 \mathrm{~ms}$ and $895 \mathrm{~ms}$ using their non-dominant hand, achieving maximal force generation of $34.7 \mathrm{~kg}$ and $33.1 \mathrm{~kg}$ respectively. Time between consecutive cycles was minimal at less than $100 \mathrm{~ms}$ bilaterally. There were no statistical differences between dominant and non-dominant upper-limbs of the control group on force and time based measures of hand function.

The average cycle completion time for the post-stroke group was $2081 \mathrm{~ms}$ with their affected hand, and $1265 \mathrm{~ms}$ 


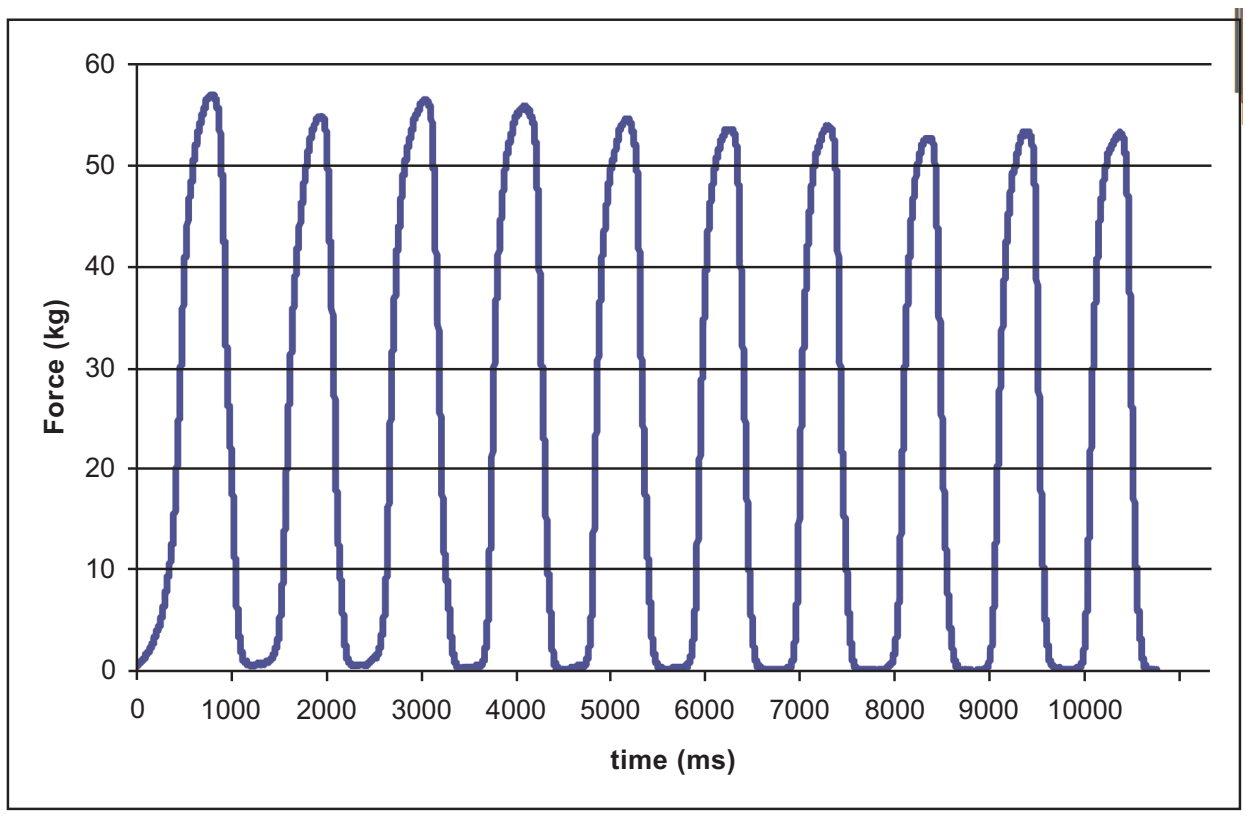

Fig. (3). Force curve for a right handed male control: repeated maximal contraction and relaxation.

with their non-affected hand. Maximal force achieved by the post-stroke group using their affected upper-limb was significantly lower $(5.6 \mathrm{~kg})$ than the maximal force achieved using the non-affected upper-limb $(25.0 \mathrm{~kg} ; \mathrm{z}=-2.02, \mathrm{p}=$ $0.04)$. The reduced maximal force indicates significant weakness in the affected upper-limb of the tested subjects in the post-stroke group.

Contraction-relaxation cycle time, and the time lapse between cycles, was considerably longer in the post-stroke group for both the affected and non-affected limbs (refer to
Table 2); however differences between the affected and nonaffected limb did not reach statistical significance. Increased time to complete cycles suggests slower motor recruitment patterns when executing hand grip contraction and relaxation in the post-stroke group. Longer time between repeated cycles suggests difficulty resuming the contraction phase of the task after relaxing, potentially due to slower muscle recruitment, biomechanical changes after the preceding contraction phase and/or motor planning difficulties.

Table 2. Hand Grip Variables for Dominant and Non-Dominant Upper-Limbs of the Control Group, Non-Affected and Affected Upper-Limbs of the Post-Stroke Group

\begin{tabular}{|c|c|c|c|c|}
\hline & \multicolumn{2}{|c|}{ Control Group (n=5) } & \multicolumn{2}{|c|}{ Post-Stroke Group $(n=5)$} \\
\hline Force $\max (\mathrm{kg})$ & $34.7 \pm 16.2$ & $33.1 \pm 15.0$ & $25.0 \pm 18.2$ & $5.6 \pm 1.5^{\mathrm{a}}$ \\
\hline Time betw cycles (ms) & $90.8 \pm 92.4$ & $100.2 \pm 122.4$ & $363.9 \pm 302.7$ & $845.1 \pm 684.3$ \\
\hline $\mathrm{F}_{\mathrm{vel}} \min \left(\mathrm{kgms}^{-1}\right)$ & $-0.33 \pm 0.16$ & $-0.30 \pm 0.16$ & $-0.22 \pm 0.20$ & $-0.03 \pm 0.03^{\mathrm{a}}$ \\
\hline Time to $\mathrm{F}_{\mathrm{vel}} \max (\mathrm{ms})$ & $197.3 \pm 82.5$ & $204.1 \pm 67.9$ & $364.9 \pm 107.7^{b}$ & $260.3 \pm 128.9$ \\
\hline Time to $F_{\text {vel }} \min (\mathrm{ms})$ & $666.9 \pm 281.0$ & $700.6 \pm 334.2$ & $1059.6 \pm 337.9$ & $1349.8 \pm 569.4$ \\
\hline \multicolumn{5}{|l|}{ Grip work (kg.s) } \\
\hline$\%$ involuntary work & $2.7 \pm 0.87$ & $3.3 \pm 0.87$ & $3.8 \pm 1.6$ & $39.2 \pm 28.5^{\mathrm{a}}$ \\
\hline
\end{tabular}

Notes: All values are averaged over available cycles for each subject, expressed as mean \pm SD.

$\mathrm{F}_{\mathrm{vel}} \max =$ fastest rate of contraction, $\mathrm{F}_{\mathrm{vel}} \mathrm{min}=$ fastest rate of relaxation, kg.s = kilogram seconds.

${ }^{\mathrm{a}} \mathrm{p} \leq .05$ paired comparison affected and non-affected limb of post-stroke group.

${ }^{b} \mathrm{p} \leq .05$ group comparison between non-affected limb of post-stroke group and dominant limb of the control group. 


\section{Force Velocity}

The control group achieved maximal force velocities of $0.23 \mathrm{kgms}^{-1}$ and $0.21 \mathrm{kgms}^{-1}$ with dominant and nondominant upper-limbs; and maximal rate of relaxation was $-0.33 \mathrm{kgms}^{-1}$ and $-0.30 \mathrm{kgms}^{-1}$ respectively. Differences between dominant and non-dominant upper-limbs did not reach statistical significance in the control group, suggesting that mechanisms controlling the rate at which muscles contract and relax are similar for the control group irrespective of hand dominance. In contrast, the rate at which the post-stroke group contracted and relaxed was significantly slower on the affected side than the nonaffected side (refer to Table 2). The post-stroke group achieved maximal force velocities of $0.02 \mathrm{kgms}^{-1}$ and 0.11 $\mathrm{kgms}^{-1}$ with affected and non-affected upper-limbs $(\mathrm{z}=$ $2.02, \mathrm{p}=0.04)$; and maximal relaxation rate of $-0.03 \mathrm{kgms}^{-1}$ and $-0.22 \mathrm{kgms}^{-1}$ respectively $(\mathrm{z}=-2.02, \mathrm{p}=0.04)$.

The time required to reach maximal and minimal velocity (from the start of muscle contraction) was very similar for dominant and non-dominant upper-limbs of the control group (refer to Table 2), further supporting the suggestion that mechanisms controlling the rate at which muscles contract and relax are similar for the control group irrespective of hand dominance. In contrast, the post-stroke group demonstrated a slowing of these mechanisms, indicated by longer time to achieve maximal and minimal force velocity for both the affected and non-affected upperlimbs (refer to Table 2). The differences between affected and non-affected upper-limbs were not significanct.

\section{Grip Work}

Similar amounts of grip work were performed by the control group's dominant and non-dominant upper-limbs during task-specific phases of the cycle (14.4 kg.s and 14.3 kg.s respectively) and during non-task specific phases $(0.33$ kg.s and 0.45 kg.s). Minimal work was performed between cycles, contributing to a small amount of involuntary work as a percentage of the overall grip work performed. The control group were able to direct approximately $97 \%$ of the overall grip work towards the specific demands of the task: contracting and relaxing their hand. Differences between grip work for the control group's dominant and nondominant upper-limbs were not significant.

In comparison, the degree of task-specific grip work performed by the post-stroke groups' affected upper-limb was very small (3.8 kg.s), considerably less than the grip work performed by the non-affected upper limb (17.1 kg.s). While the post-stroke group performed less task-specific work with their affected upper-limb, they performed more non-task specific work (refer to Table 2). Increased non-task, or involuntary work, significantly reduces efficiency. Involuntary work occurring between repeated cycles suggests an inability to 'turn off' the preceding muscle contraction and commence the next contraction. This overactivity was most evident in adults with positive UMN features such as spasticity. The involuntary grip work observed in the affected limb of the post-stroke group was significantly greater than the involuntary grip work performed with the non-affected upper-limb $(\mathrm{z}=-2.02, \mathrm{p}=$ $0.04)$.
Motor performance of the non-affected upper-limb of the post-stroke group and the dominant limb of the control group were compared to check the veracity of the third hypothesis. This analysis revealed a statistically significant difference for time to achieve maximal $\mathrm{F}_{\mathrm{vel}}(\mathrm{z}=-2.4, \mathrm{p}=0.02)$, and $\mathrm{a}$ clear trend towards lower force and slower force velocity values when comparing the post-stroke group's non-affected limb with the dominant limb of the control group.

\section{DISCUSSION}

This paper presents a methodology for quantifying both positive and negative aspects of UMN syndromes during a functional hand grasp and release task. The paradigm was piloted on 5 post-stroke subjects and an age, sex and handdominance matched control group. With the resultant data, two of three hypotheses were confirmed; namely the equivalence of dominant and non-dominant upper-limbs of the control group and the significant difference between affected and non-affected upper-limbs of the post-stroke group.

The computerised dynamometry paradigm enabled continuous measurement of force and time based aspects of performance throughout the task, permitting calculation of force velocity through both contraction and relaxation phases. Not only did the post-stroke group produce significantly less force with their affected limb, this force was produced at a significantly slower rate; therefore maximal force velocity (maximal rate of contraction) was severely impaired. These findings are typical of adults with negative UMN features such as weakness, reduced motor control, and fatigue. The post-stroke group also showed extended time to achieve maximal relaxation (therefore reduced minimum force velocity).

In addition, the post-stroke group required increased time between consecutive cycles of contraction-relaxation (transition phase), suggesting difficulty voluntarily 'turningoff' a contraction before preparing to commence the next. This was particularly evident in adults with strong positive UMN features such as spasticity and hypertonia. Subjects in the post-stroke group with upper-limb flexor posturing that became more apparent on effort, interpreted as inducible motor overactivity, appeared to have the longest cycle times and produced the greatest amount of involuntary grip work.

The grip work concept introduced in this paper has been adapted from earlier studies of isometric grip work [35, 36]. Taken over 9 cycles, total grip work is representative of the amount of work a person performs during the task. In this paradigm, grip work was separated into task-specific work, non-task specific work, and work between cycles. Summing the latter two values gives an estimation of involuntary grip work, an essentially non-functional component of the contraction-relaxation cycle that has the capacity to interfere with controlled task performance. Control subjects in this study exhibited minimal involuntary grip work (3\%), demonstrating controlled task performance, with $97 \%$ of the overall grip work being targeted towards task-specific work. In clear contrast, $40 \%$ of the overall grip work performed by the affected hand of subjects in the post-stroke group was not directed towards the task. High levels of involuntary grip work were observed in participants with significant positive UMN features such as spastic dystonia, producing persistent 
contraction of the wrist and fingers during attempts to release the fingers.

Interestingly, the third hypothesis was not supported. It is generally assumed that the non-affected limb of a person post-stroke is representative of their pre-stroke 'normal' state. Furthermore, in patients experiencing a severe loss of function in their dominant affected limb, it is presumed that dominance switches to their non-affected limb. In this way, the findings of differences (significant or trends) between control and non-affected post-stroke upper-limb data was an unexpected finding. However, this finding is in keeping with studies of post-stroke gait, that have identified changes in the non-affected lower-limb of adults with stroke reflecting increased time requirements to complete a walking task [38, 39] and in fMRI studies of hand function [40]. If confirmed in a larger sample, this would draw into question the common clinical practice of assuming that the function of the non-affected upper-limb of post-stroke patients is normal after an ipsilateral stroke.

The electronic dynamometry technique piloted in this study provides a number of theoretical and clinical advantages over previously reported protocols. First, grasping and releasing an object is a simple functional task undertaken by predictable and reproducible sets of muscles. In this case, the electronic dynamometer was the 'object' through which force and time data were measured. Unlike most previous approaches, this technique has the advantage of producing quantitative data during a routine functional task in which the person actively participates, rather than evaluating impairment using passive assessment techniques. A further theoretical advantage of this approach is the capacity to quantify both negative and positive features of UMN syndromes, as recommended by the European consensus paper [41]. It is clear that both components impact upon upper limb function and it is not ecologically valid to separate negative and positive features out from one another during assessment. Measuring both aspects within the same paradigm represents a person-centred theoretical construct.

Finally, the data collection process was readily implemented in the clinical context of an outpatient spasticity clinic, as part of the typical clinical assessment procedure. Piloting the procedure highlighted the sensitivity of the dynamometer, enabling recording of grip force as low as $20 \mathrm{~g}$, and confirmed that even patients with severe 'spasticity' and minimal voluntary motor activity were able to hold and apply measurable pressure to the hand dynamometer. This observation negates some of the limitations inherent in other devices and produces less of a floor effect than observed in other tools.

\section{Limitations}

These preliminary findings, while promising, are derived from a small sample of adults with functional upper-limb difficulties following UMN lesion. The capacity for measuring both positive and negative features of the UMN syndrome requires validation against existing measurement procedures and tools, and measures of upper-limb function in larger samples. The introduced concept of grip work appears to be a robust and conceptually sound measurement of voluntary and involuntary activity; however future studies are required to elaborate on this preliminary concept. The reliability and validity of the technique require assessment in future studies. Finally, the clinical utility of the paradigm in relation to measurement of treatment efficacy remains an area for future research.

\section{CONCLUSION}

This pilot study applied a novel vector analytic model to a well established data collection method (hand dynamometry) to measure the potential effects of UMN lesion on hand function. Of particular clinical importance, the data collection and analysis paradigm enabled simultaneous quantification of both positive and negative UMN features within the same individual. This methodology addresses many of the requirements called on for the measurement of upper-limb 'spasticity', acknowledging the complex nature of spasticity assessment by producing more than one 'value', by measuring the effect of UMN syndrome during an active, functional task [23], and by simultaneously considering the effect of positive and negative features of the UMN syndrome [41]. The technique appears to have greater ecological validity and fewer limitations compared to previous measures.

\section{ACKNOWLEDGEMENT}

This study was supported by an unrestricted Independent Investigatory Grant from Ipsen Pty Ltd.

\section{REFERENCES}

[1] Barnes MP, Johnson GR. Upper Motor Neurone Syndrome and Spasticity. Cambridge: Cambridge University Press 2001.

[2] Pohl M, Mehrholz J, Rockstroh G, Ruckriem S, Koch R. Contractures and involuntary muscle overactivity in severe brain injury. Brain Inj 2007; 21(4): 421-32.

[3] Ada L, O'Dwyer N, O'Neill E. Relation between spasticity, weakness and contracture of the elbow flexors and upper limb activity after stroke: An observational study. Disabil Rehabil 2006; 28(13): 891-7.

[4] Kamper DG, Fischer HC, Cruz EG, Rymer WZ. Weakness is the primary contributor to finger impairment in chronic stroke. Arch Phys Med Rehabil 2006; 87(9): 1262-9.

[5] Burridge JH, Turk R, Notley SV, Pickering RM, Simpson DM. The relationship between upper limb activity and impairment in poststroke hemiplegia. Disabil Rehabil 2009; 31(2): 109-17.

[6] Lance JW, Feldman RG, Young RR, Koella WP. Symposium synopsis. Spasticity: disordered motor control. Chicago: Year Book Medical Publishers 1980.

[7] Ivanhoe CB, Reistetter TA. Spasticity: the misunderstood part of the upper motor neuron syndrome. Am J Phys Med Rehabil 2004; 83(10 Suppl): S3-9.

[8] Patrick E, Ada L. The Tardieu Scale differentiates contracture from spasticity whereas the Ashworth Scale is confounded by it. Clin Rehabil 2006; 20(2): 173-82.

[9] Mehrholz J, Wagner K, Meissner D, et al. Reliability of the Modified Tardieu Scale and the Modified Ashworth Scale in adult patients with severe brain injury: a comparison study. Clin Rehabil 2005; 19(7): 751-9.

[10] Bohannon RW, Smith MB. Interrater reliability of a Modified Ashworth Scale of muscle spasticity. Phys Ther 1987; 67(2): 2067.

[11] Elovic EP, Simone LK, Zafonte R. Outcome assessment for spasticity management in the patient with traumatic brain injury: the state of the art. J Head Trauma Rehabil 2004; 19(2): 155-77.

[12] Allison SC, Abraham LD, Petersen CL. Reliability of the Modified Ashworth Scale in the assessment of plantarflexor muscle spasticity in patients with traumatic brain injury. Int J Rehabil Res 1996; 19(1): 67-78.

[13] Kumar RT, Pandyan AD, Sharma AK. Biomechanical measurement of post-stroke spasticity. Age Ageing 2006; 35(4): 371-5. 
[14] Stucki G. International Classification of Functioning, Disability, and Health (ICF): a promising framework and classification for rehabilitation medicine. Am J Phys Med Rehabil 2005; 84(10): 733-40.

[15] Katz RT, Rovai GP, Brait C, Rymer WZ. Objective quantification of spastic hypertonia: correlation with clinical findings. Arch Phys Med Rehabil 1992; 73(4): 339-47.

[16] Snow BJ, Tsui JK, Bhatt MH, Varelas M, Hahimotot SA, Calne DB. Treatment of spasticity with botulinum toxin: a double-blind study. Ann Neuro 1990; 28(4): 512-5.

[17] Bhakta BB, Cozens JA, Chamberlain MA, Bamford JM. Impact of botulinum toxin type A on disability and carer burden due to arm spasticity after stroke: a randomised double blind placebo controlled trial. J Neurol Neurosurg Psychiatry 2000; 69(2): 21721. Erratum in: J Neurol Neurosurg Psychiatry 2001; 70(6): 821.

[18] Singer BJ, Singer KP, Allison GT. Evaluation of extensibility, passive torque and stretch reflex responses in triceps surae muscles following serial casting to correct spastic equinovarus deformity. Brain Inj 2003; 17(4): 309-24

[19] Baguley IJ, Bailey KM, Slewa-Younan S. Prolonged anti-spasticity effects of bolus intrathecal baclofen. Brain Inj 2005; 19(7): 545-8.

[20] Rose V, Shah S. A comparative study on the immediate effects of hand orthoses on reduction of hypertonus. Aust Occup Ther J 1987; 34(2): 59-64.

[21] Harvey L, King M, Herbert R. Test-retest reliability if a procedure for measuring extensibility of the extrinsic finger flexor muscles. J Hand Ther 1994; 7: 251-4.

[22] McPherson JJ, Kreimeyer D, Aalderks M. A comparison of dorsal and volar resting hand splints in the reduction of hypertonus. Am J Occup Ther 1982; 36(10): 664-70.

[23] Burridge JH, Wood DE, Hermens HJ, et al. Theoretical and methodological considerations in the measurement of spasticity. Disabil Rehabil 2005; 27(1-2): 69-80.

[24] van Meeteren J, van Rijn RM, Selles RW, Roebroeck ME, Stam HJ. Grip strength parameters and functional activities in young adults with unilateral cerebral palsy compared with healthy subjects. J Rehabil Med 2007; 39(8): 598-604.

[25] Innes E. Handgrip strength testing: a review of the literature. Aust Occup Ther J 1999; 46(3): 120-40.

[26] Shechtman O, Davenport R, Malcolm M, Nabavi D. Reliability and validity of the BTE-Primus grip tool. J Hand Ther 2003; 16(1): 3642 .

[27] Massy-Westropp N, Rankin W, Ahern M, Krishnan J, Hearn TC. Measuring grip strength in normal adults: reference ranges and a comparison of electronic and hydraulic instruments. J Hand Surg Am 2004; 29A(3): 514-9.
[28] Blennerhassett JM, Matyas TA, Carey LM. Impaired discrimination of surface friction contributes to pinch grip deficit after stroke. Neurorehabil Neural Repair 2007; 21(3): 263-71.

[29] McDonnell MN, Hillier SL, Ridding MC, Miles TS. Impairments in precision grip correlate with functional measures in adult hemiplegia. Clin Neurophys 2006; 117(7): 1474-80.

[30] Woldag $\mathrm{H}$, Hummelsheim $\mathrm{H}$. Is the reduction of spasticity by botulinum toxin a beneficial for the recovery of motor function of arm and hand in stroke patients? Eur Neurol 2003; 50(3): 165-71.

[31] Bhakta BB, O'Connor RJ, Cozens JA. Associated reactions after stroke: a randomized controlled trial of the effect of botulinum toxin type A. J Rehabil Med 2008; 40(1): 36-41.

[32] Bhakta BB, Cozens JA, Chamberlain MA, Bamford JM. Quantifying associated reactions in the paretic arm in stroke and their relationship to spasticity. Clin Rehabil 2001; 15(2): 195-206.

[33] Ashton LA, Myers S. Serial grip strength testing. Its role in assessment of wrist and hand disability. Internet J Surg 2004; 5(2). www.ispub.com/journal/the_internet_journal_of_surgery.html

[34] Smith GA, Nelson RC, Sadoff SJ, Sadoff AM. Assessing sincerity of effort in maximal grip strength tests. Am J Phys Med Rehabil 1989; 68(2): 73-80.

[35] Bautmans I, Gorus E, Njemini R, Mets T. Handgrip performance in relation to self-perceived fatigue, physical functioning and circulating IL-6 in elderly persons without inflammation. BMC Geriatr 2007; 7(5): 1-8.

[36] Bautmans I, Njemini R, Predom H, Lemper JC, Mets T. Muscle endurance in elderly nursing home residents is related to fatigue perception, mobility, and circulating tumor necrosis factor-alpha, interleukin-6, and heat shock protein 70. J Am Geriatr Soc 2008; 56(3): 389-96.

[37] Kurillo G, Gregoric M, Goljar N, Bajd T. Grip force tracking system for assessment and rehabilitation of hand function. Technol Health Care 2005; 13(3): 137-49.

[38] Titianova EB, Peurala SH, Pitkanen K, Tarkka IM. Gait reveals bilateral adaptation of motor control in patients with chronic unilateral stroke. Aging Clin Exp Res 2008; 20(2): 131-8.

[39] Titianova EB, Mateev PS, Peurala SH, Sivenius J, Tarkka IM. Footprint peak time and functional ambulation profile reflect the potential for hemiparetic gait recovery. Brain Inj 2005; 19(8): 62331.

[40] Grefkes C, Nowak DA, Elickhoff SB, et al. Cortical connectivity after subcortical stroke assessed with functional magnetic resonance imaging. Ann Neurol 2008; 63(2): 236-46.

[41] Wissel J, Ward AB, Ertzgaard P, et al. European consensus table on the use of botulinum toxin type $\mathrm{A}$ in adult spasticity. J Rehabil Med 2009; 41(1): 13-25. 